\title{
Sacralidad y gobierno, la visita pastoral de Francisco Aguiar y Seijas al Sur del Arzobispado de México (1687-1688): una mitra itinerante
}

Sacredness and government, the pastoral visit of Francisco Aguiar and Seijas, to the South of the Archbishopric of Mexico (1687-1688): an itinerant miter

\section{Berenise BRAVO RUBIO \\ ENAH-INAH \\ berenise_bravo@inah.gob.mx}

Resumen: El presente artículo analiza la visita que el arzobispo Francisco Aguiar y Seijas realizó al Sur del Arzobispado de México, es decir, a las parroquias ubicadas entre el Valle de Cuernavaca y aquellas de la jurisdicción de Tixtla, Iguala y Chilapa entre noviembre de 1687 y enero de 1688. Este artículo pretende mostrar cómo las visitas a las 19 parroquias del sur abrieron un tiempo efímero y sacro en el que el prelado celebró una diversidad de misas, procesiones, y confirmaciones, pero también un espacio y tiempo en el que atendió, con auxilio de su comitiva, en una especie de mitra itinerante, diversos asuntos de gobierno y justicia, tanto de las parroquias sujetas a visita como entre las que no.

Palabras clave: arzobispado de México; Francisco Aguiar y Seijas; Sacralidad; Gobierno; mitra itinerante.

Antes de la media noche el arzobispo de México, acompañado de sus capellanes, predicadores y notarios, salió del paraje de Mezcala y se dirigió al borde del río que se encontraba muy cerca de dicho lugar ${ }^{1}$. Allí esperó unas balsas y a las 12 de la noche del lunes 22 de diciembre de 1687 subió a una de ellas.

1 Mexcala / Mezcala se encuentra en el actual estado de Guerrero en México. 
El arzobispo y su comitiva después de cuatro horas «balseando el río» llegó al pueblo de Palula. En este paraje durmió y desde él salió a las dos de la noche con los eclesiásticos que lo acompañaban para llegar a Tepecuacuilco. A esta parroquia arribó el 24 de diciembre y fue recibido por las autoridades civiles y eclesiásticas en medio de júbilo y del toque de campanas. El arzobispo durante su trayecto desde Zupango del Río a Tepecoacuilco había recorrido 21 leguas y descansado en tres parejas (Barranca del Zopilote, Mezcala y Polula) donde, a falta de iglesia o capillas, había celebrado misas en altares portátiles construidos con unas cuantas ramas ${ }^{2}$. El prelado, durante los tres días que le llevó llegar de un punto a otro, había caminado o balseado de noche, siempre de noche. La razón era sencilla, nadie podría hacerlo de día en aquellas zonas tan agrestes, solas y dilatadas donde lo único cierto y presente era el inclemente sol ${ }^{3}$. Las condiciones del clima y los inhóspitos lugares se convertían así en dos factores que dificultaban la visita de los prelados al denominado «Sur del arzobispado», es decir a las parroquias que se ubicaban más allá del valle de Cuernavaca y cuyo punto limítrofe era el puerto de los Reyes en Acapulco. Las dificultades de llegar hasta este puerto eran tan evidentes que el mismo arzobispo lo manifestó en la carta cordillera de Acapulco que envió a los curas y doctrineros el 13 de noviembre de $1687^{4}$. En dicha carta comunicó la realización de la visita pastoral pero advirtió que llegando a Coyuca «de no haber accidente al tiempo... se pasara a dicho puerto». Y en efecto, hubo un accidente. El prelado, que aquel año contaba 56 años de edad, por razones de salud tuvo que suspender la visita y regresar a México y así lo comunicó al Rey en mayo de $1688^{5}$. El prelado nunca reanudó la visita y de hecho y hasta donde sabemos, sólo un arzobispo logró llegar al puerto, su sucesor en la mitra: José Lanciego y Eguilaz. Este prelado arribó al puerto de Acapulco en el año de 1721. En aquella ocasión, ante tal acontecimiento, inusual e importante, los fieles de Acapulco lo recibieron con salvas de cañón ${ }^{6}$.

2 Washington D. C, Library of Congress, Pastoral Box 14, Visita al sur del arzobispado de Francisco Aguiar y Seijas, 1687-1688.

3 En Mezcala por ejemplo las temperaturas más bajas son en diciembre y éstas alcanzan los 24 grados.

4 La carta cordillera se encuentra en las primeras fojas el libro de visita.

5 La referencia de la carta enviada al Rey comunicando que no había logrado tocar el puerto de Acapulco se encuentra en Rocio Silva Herrera, Francisco Aguiar y Seijas, pastor del rebaño, en Cuadernos de estudios Gallegos, LXI, no. 127 (enero-diciembre de 2014) pp. 117-142

6 MÉxico, ArChivo GenEral de la NACIÓn, Bienes Nacionales, Diario de la Visita a Acapulco, 1720-1721, vol. 87, exp. 17. 
Aunque el arzobispo no llegó hasta el puerto de Acapulco sí logró internarse y llegar a ciertas parroquias localizadas entre las jurisdicciones de Tixtla, Chilapa e Iguala. Y de este recorrido, es decir, del que hizo por 19 parroquias desde Cuernavaca hasta el Sur, existe un testimonio manuscrito elaborado por el secretario de visita de Aguiar y Seijas, Felipe Deza y Ulloa, conocido como libro de visita al sur del arzobispado. A través de este manuscrito, del que recientemente se supo su localización, podemos saber cuáles eran las condiciones de aquellos curatos tan alejados, conocer el estado material y espiritual de aquellas feligresías, su número de fieles, sus cofradías, sus problemas locales particulares pero también conocer, cómo el prelado, a pesar de estar fuera de su sede episcopal y de volcarse a este tiempo efímero ${ }^{7}$ que era la visita pastoral y que se caracterizaba por la sacralización propuesta por Trento ${ }^{8}$, iba en el trayecto despachando asuntos de diferente índole y orden en una especie de mitra itinerante. Asuntos que atañían particularmente a la administración y justicia de su jurisdicción y que el arzobispo no podía dejar de despachar o resolver. Una mitra itinerante que el arzobispo activó en cada ocasión, de las cinco veces, que salió en visita episcopal desde la ciudad de México. Esta última ciudad que era la sede del arzobispado y por lo tanto de su Curia o Sagrada Mitra. El objetivo de este artículo es precisamente mostrar por un lado cómo fue este tiempo efímero, qué espacios y tiempos sagrados vivió, qué asuntos locales resolvió y por el otro, ejemplificar cómo era esta curia itinerante, es decir, mostrar y analizar qué asuntos resolvió durante el trayecto que atañían a otras parroquias que en aquel momento no eran sujetas de visita. En este sentido pretendemos analizar cómo esta actividad era justo una demostración de su figura pastoral y de reafirmación de su jurisdicción episcopal.

\section{Piedra DE TOQUe. La VISITA PASTORAL DE Francisco AgUtar y SEIJAS}

Una de las actividades que caracterizó la gestión episcopal de Francisco Aguiar y Seijas como obispo de la diócesis de Michoacán fue la visita pastoral. Esta actividad fue «la piedra de toque» de su gobierno. En efecto, Aguiar, promovido a dicha diócesis en 1679, recorrió esta jurisdicción entre septiembre de dicho año

7 Efímero en tanto que la visita se convertía en un régimen temporal de carácter excepcional donde se daba apertura a una «temporalidad generadora de símbolos, de signos culturales». Fernando

DE LA FLOR, Barroco. Representación e ideología en el mundo hispano (1580-1680), España, 2002, p. 163.

8 Es decir, por la celebración del prelado de innumerables misas, procesiones, rezo de rosarios, confesiones, explicaciones sobre la doctrina y la predicación de sermones, 
y marzo de 1681 con el firme deseo de reconocer el estado de su diócesis para su mejor gobierno9 . Durante su visita pastoral se había internado en lugares en donde jamás había llegado obispo alguno, como en la serranía del Río Verde, considerada en aquellos años, tierra de misiones. Justo durante esta visita Aguiar y Seijas recibió la noticia de su presentación para gobernar la jurisdicción eclesiástica más grande, poblada y diversa del imperio español en América: el arzobispado de México. El 2 de enero de 1682 tomó posesión de la mitra del arzobispado y en ella permaneció hasta su muerte ocurrida en $1698^{10}$. Como arzobispo de México fue reconocido por sus contemporáneos, y así lo muestran algunos estudios actuales, por su ascetismo, por su caridad, por su empeño en fundar casas de recogimiento y por su afán reformador de la vida conventual femenina. ${ }^{11}$ Sin embargo, pocos han señalado su enorme compromiso por la reforma de la iglesia diocesana y vehemente deseo de hacer cumplir el concilio de Trento, particularmente con la creación del Seminario Conciliar Tridentino y con la realización de la visita pastoral. Sobre esto último debemos señalar que, con la experiencia anterior en territorio vallisoletano, Aguiar y Seijas sabía bien que la visita pastoral le permitiría reconocer y gobernar su nueva jurisdicción, así que esta actividad, mandatada además por el Tercer Concilio Provincial Mexicano ${ }^{12}$, la «privilegió al grado de elevarla a la principal forma de su ges-

9 Sobre su gestión episcopal en aquella diócesis ver Alberto CARRILlo CAZARES, el obispo Aguiar y Seijas: su perfil pastoral en Michoacán (1678-1682), en Josefina MURIEL, el arzobispo Francisco Aguiar y Seijas, México, 2000, pp. 27 a 46. Alberto CARILlO CAZARES, Michoacán en el otoño del siglo XVII, Morelia Michoacán, 1993.

10 Datos biográficos y perfil pastoral se encuentran en tres sermones fúnebres. Entre ellos, destaca el de su confesor. MS, MÉXICO, Biblioteca NaCIOnal, Fondo RESERVAdo LaFRagua, Francisco Lezamis, Breve relación de la vida y muerte del Ilustisimo Señor doctor Francisco Aguiar y Seijas dedicado al ilustrísimo cabildo catedral de Galicia 1699. LAF 574. Otro sermón es: MS, MÉXICO, BIBLIOTECA NACIONAL, FONDO RESERVADO LAFRAGUA, Transformación Theopolitica idea mitológica del príncipe pastor sagrado proteo: Alegorizada en imágenes, descifrada en números que el aparato magnifico al ilustrísimo Aguiar y Seijas y Ulloa que da siempre Augusta Iglesia Metropolitana, 1683. LAF 1290.

11 Sobre las personalidad del arzobispo y reformas a los conventos de religiosas ver: Antonio RUBIAL GARCÍA, Las monjas se inconforman: los bienes de Sor Juana en el espolio del arzobispo Francisco Aguiar y Seijas en Biblioteca Virtual Universal (2005).

12 El obispo por si mismo debe visitar cada año su propia diócesis, o a lo menos cada dos años. Libro III de la visita a la propia provincia, Título I al VIII. Libro Quinto de las Visitas, título I al XIII, MS, MÉXICO, BiblioteCA ARCHIVO HISTÓRICO DEL ARZOBISPADO DE MÉXICO, Concilio III provincial mexicano celebrado en México en el año de 1585, confirmado en Roma por el Papa Sixto V y mandado observar por el gobierno español en diversas órdenes Ilustrado con muchas notas por el reverendo padre Basilio Arrillaga de la Compañía de Jesús, Barcelona, Manuel Miro y D. Marsa, 1870. La visita pastoral como obligación también aparecen en los textos reales. «La disposición básica en lo que se decreta y regula el régimen de visitas eclesiásticas es la de Felipe II, firmada en san Lorenzo el 5 de agosto de 1577, ampliada y matizada por otras posteriores (cinco en total) de Felipe III y Felipe IV». Está recogida en la Recopilación de 1680 en la ley XXIV, título VII, Libro I, «sobre arzobispos y obispos». 
tión episcopal». En efecto, el arzobispo, a los casi dos años de su toma de posesión, decidió emprender la visita pastoral por toda su jurisdicción cuyo limite al norte era Tampico y por el sur Acapulco. Recorrerla le llevaría más de cuatro años y para ello emprendió cinco derroteros. El primero dirigido a visitar las parroquias de la Sierra Baja, Huasteca, Sierra Alta y Tampico lo efectuó entre el 3 de noviembre de 1683 hasta el 9 de junio de $1684^{13}$. En el segundo se encaminó hacía Tacubaya y el fértil y poblado valle de Toluca. Esta visita la realizó entre el 21 de noviembre de 1684 y 13 de noviembre de $1685^{14}$. Un tercer derrotero lo emprendió desde Cuautitlán hacía Tepeji y Querétaro entre el 9 de noviembre de 1685 y de 16 de abril de $1686{ }^{15}$. En el cuarto derrotero visitó las parroquias y doctrinas de Chalco, Valle de Amilpas, Xochimilco y Coyoacán entre el 4 de diciembre de 1686 y 9 de abril de $1687^{16}$ y finalmente, con el deseo de llegar al puerto de Acapulco, emprendió la visita el 26 de noviembre de 1687 saliendo por San Agustín de las Cuevas, pasando por Cuernavaca hasta alcanzar las parroquias de la jurisdicción de Tixtla e Iguala. Esta última visita la concluyó en enero de 1688. Veamos entonces cuál fue el estado material y espiritual que el prelado encontró durante esta última visita.

\section{LA VISITA AL SUR. ENTRE LA SACRALIDAD Y EL ORDEN}

Durante dos meses el arzobispo y su comitiva, es decir, notarios y predicadores en lengua, uno de ellos jesuita, José Capetillo, caminaron, montaron y balsearon con el fin de llegar al puerto de Acapulco. Como hemos mencionado líneas adelante, la visita al sur representaba para cada arzobispo un verdadero reto, no solo por los agrestes caminos, altas temperaturas o los caudalosos ríos que debían

José Luis MORADA MERIDA, La visita eclesiástica como institución en Indias en Fabrbuch für Geschichte Lateinamerikas, Anuario de Historia de América Latina, Alemania (1998), p. 61.

13 MÉxico, ArChivo Historico del ARZobispado De México, Fondo Episcopal, Libro de visita del ilustrísimo señor Francisco Aguiar Seijas (1683-1684) CL19. 711 fojas. La visita ha sido estudiada por Berenise BRAVO RUBIO y Marco Antonio PÉREZ ITURBE, Tiempos y Espacios religiosos novohispano. La visita pastoral de Francisco Aguiar y Seijas 1683-1684, en Alicia MAYER y Ernesto DE LA TORRE DEL VILlaR (coords.), Religión, poder y sociedad en la Nueva España, México, 2004, pp. 67-83.

14 MÉXICO, ArChivo Historico DEl ARZObisPado DE MÉXICO, Fondo Episcopal, Libro de visita del ilustrísimo señor Francisco Aguiar Seijas (1683-1684) CL19. 711 fojas.

15 MÉXICO, ARChIVO GENERAL DE LA NACIÓN, Bienes Nacionales, Libro de visita pastoral (16851686), vol. 475, exp1, 1-368.

16 MÉXICO, ARChivo General de la Nación, Bienes Nacionales, Libro de visita pastoral (16861687), vol. 460, exp. 35, 1-315. Esta visita ha sido estudiada por Estudiada por Rocío SILVA Herrera, Francisco Aguiar y Seijas, pastor del rebaño, en Cuadernos de estudios Gallegos, LXI, no. 127 (enero-diciembre de 2014) pp. 117-142. 
de cruzar, sino porque a diferencia de otras zonas, el Sur, excepto por Cuernavaca, se distinguía por la ausencia en el camino de parroquias o conventos donde pudieran alojarse. Esto significó que el arzobispo y su comitiva recorrieron largas jornadas por desolados parajes sin encontrar un solo caserío o enramada donde apear y descansar a pesar de que en la carta cordillera el arzobispo había solicitado expresamente que se alistaran además de los caminos los «parajes conforme a las distancias en forma proporcionada de manera que con alivio se pueda ir pasando». Tan solo, y como hemos mencionado, en su camino desde Zupango del Río y hasta Tepecuacuilco, jurisdicción de Iguala, había 21 leguas y en el camino sólo halló parajes y en uno de ellos llamado el Zopilote durmió en una enramada, Así que, caminos desiertos, sitios despoblados y una evidente pobreza material visible en las iglesias y conventos es lo que constató y registró durante su visita. Una extrema pobreza que evidentemente contrastaba con las magníficas iglesias y las numerosas capillas de las haciendas que estaban perfectamente construidas y aderezadas y que lucían preciosos ornamentos gracias a las limosnas, contribuciones y aranceles de las numerosas feligresías que habitaban el rico y fértil valle de Cuernavaca.

Francisco Aguiar y Seijas visitó y supervisó, entre el valle de Cuernavaca y la zona sur, 19 parroquias de las cerca de 25 que pensaba recorrer ${ }^{17}$. Diez de estas parroquias se encontraban en el valle de Cuernavaca en la jurisdicción de la villa del mismo nombre y de la de Yautepec, siete parroquias estaba en la zona sur entre la jurisdicción de Iguala, Chilapa y Tixtla y una parroquia, San Agustín Toliman, era visita de Acosautitlan del obispado de Puebla. ${ }^{18}$ Esta última parroquia la visitó sobre todo con el fin de descansar y ello con previa licencia del obispo poblano. De estas 19 parroquias sabemos que cinco eran administradas por franciscanos, cuatro por dominicos y seis estaban a cargo de eclesiásticos seculares. Del resto de las parroquias, es decir de Guichilaque, Amacuzaque, San Agustín Tolliman y Tlacotepec no sabemos qué orden religiosa o tipo de clero la administraban en virtud de que el notario no lo asentó. De las 16 parroquias sabemos que 12 eran administradas por sus párrocos en lengua castellana y mexicana como se puede apreciar en el siguiente cuadro ${ }^{19}$.

17 Este número de parroquias visitadas en muchísimo menos que las 73 parroquias que visitó en su camino a la Huasteca o las 35 que supervisó en su vista a Chalco-Xochimilco

18 Sabemos que Tasmalac, Tepecuacuilco e Iguala estaban a cargo del clero secular desde 1570, la primera, 1563 la segunda y 1570 la tercera. Peter GERHARD, Geografía Histórica de la Nueva España 1519-1821, México, 1986, p. 151.

19 Los notarios no siempre anotaban con diligencia la lengua en la que se administraba el curato. 
Cuadro I. Parroquias visitadas, miembros del clero a cargo de la parroquia y lenguas en la que se la administraban sus curas de almas

\begin{tabular}{|c|c|c|c|}
\hline Parroquia & Orden religiosa & Diocesano & Lengua \\
\hline San Agustín de las Cuevas & Dominicos & & mexicano \\
\hline \multicolumn{4}{|l|}{ Guichilaque (visita de la doctrina de Cuernavaca) } \\
\hline San Juan evangelista Xochltepec & Franciscanos & & mexicano \\
\hline $\begin{array}{l}\text { San Lucas Masaltepec (jurisdicción de la villa de } \\
\text { Cuernavaca) }\end{array}$ & Franciscanos & & mexicano \\
\hline Amasetepec (pueblo y doctrina de Tialquiltenango) & Dominicos & & \\
\hline \multicolumn{4}{|l|}{ Amacuzaque } \\
\hline Tasmalac (jurisdicción de Iguala) & & secular & mexicano \\
\hline $\begin{array}{l}\text { San Juan Buatista, Atenango del Río (jurisdicción de } \\
\text { Chilapa) }\end{array}$ & & secular & mexicano \\
\hline $\begin{array}{l}\text { San Agustín Toliman (de visita de Acosautitlan del } \\
\text { obispado de la Puebla) y visita San Francisco Osomatlan }\end{array}$ & & & mexicano \\
\hline San Agustín Oapan (jurisdicción de Tixtla) & & secular & \\
\hline Santiago Zumpango del Río (jurisdicción de Tixtla) & & secular & \\
\hline \multicolumn{4}{|l|}{ Tlacotepec } \\
\hline Santa María de la Concepción, Tepecoacuilco & & secular & \\
\hline San Francisco de Iguala & & secular & mexicano \\
\hline Santo Domingo Tialquitenango & Dominicos & & mexicano \\
\hline San Miguel Tialtizapan (jurisdicción de Yautepec) & Dominicos & & mexicano \\
\hline $\begin{array}{l}\text { Santiago Xlutepec (jurisdicción de la villa de } \\
\text { Cuernavaca) }\end{array}$ & Franciscanos & & mexicano \\
\hline $\begin{array}{l}\text { Natividad de Nuestra Señora de la Asunción, } \\
\text { Cuernavaca }\end{array}$ & Franciscanos & & mexicano \\
\hline $\begin{array}{l}\text { Natividad de Nuestra Señora, Tepoztlan (jurisdicción de } \\
\text { Yautepec) }\end{array}$ & Franciscanos & & mexicano \\
\hline
\end{tabular}

Ahora bien, existían notables diferencias entre de las parroquias del límite Sur y las del valle de Cuernavaca. Estas últimas estaban densamente pobladas lo que les permitía a los curas cobrar más por servicios religiosos: Jiutepec por ejemplo, tenía 1968 feligreses y Cuernavaca 5713 fieles, en cambio Taxmalac contaba con apenas 285 fieles y San Francisco de Iguala con 403. Tan solo en la hacienda de Temixco ubicada entre Cuernavaca y Xochitepec residían 230 habitantes, es 
decir, casi el mismo número de fieles que había en Tasmalac. Por cierto, la mayor parte de los fieles de Temixco eran esclavos y mulatos negros que recibían los sacramentos y celebraban misa en la propia capilla de la hacienda.

Otra diferencia notable entre Cuernavaca y las iglesias periféricas ubicadas más al Sur era la calidad de su población. Mientras en el valle de Cuernavaca había, además de españoles, indios, cientos de esclavos negros y mulatos residentes en las parroquias de Sur, en cambio, predominaban los pueblos en que la mayor parte de los habitantes eran indios. Por ejemplo, en Tasmalac sólo había 16 españoles y mestizos frente a 285 indios y en Oapan había 833, todos indios. De hecho, la singular calidad de la población de las parroquias de Cuernavaca, obligó al prelado a renovar o autorizar más de 16 licencias para construir capillas en las haciendas para que en ellas se celebrara las misas de domingo, de guardar y algunos servicios religiosos para los esclavos o trabajadores residentes. Las dos únicas condiciones que el prelado exigió para dar la licencias fue: que en ninguna de estas capillas residieran sacerdotes y que éstas fueran construidas «lejos de los cuartos de servicio domestico». Las licencias eran solicitadas por los propios dueños de las haciendas, ranchos o trapiches y para obtenerla argumentaba la alta población residente en la unidad de producción ${ }^{20} \mathrm{o}$ ríos $\mathrm{o}$ caminos que impedían libre tránsito de sus trabajadores, por ejemplo, Francisco del Valle, dueño de un rancho de Tepetlapan ubicado en la parroquia de Santo Domingo Tlalquitenango, argumentó que el río Amacusaque era tan caudaloso que no se podía vadear. En todos los casos solicitados el arzobispo accedió porque justo este era parte sustancial de la visita: reconocer, supervisar y resolver lo más oportuno para que los fieles recibieran adecuadamente los sacramentos. En este sentido, además de capillas autorizó la construcción de iglesias y otorgó licencias para recolectar limosnas que permitieran su aderezamiento. Por ejemplo en Oapan (jurisdicción de Tixtla) ordenó recolectar limosnas para que con lo recaudado se asistiera a la obra material de dicha iglesia que estaba «mal labrada y falta de ornamentos» además de que se encontraba desaliñada su pila bautismal. Asimismo, concedió licencia de recaudar limosna a los naturales del pueblo de Tuxpa para construir su iglesia. Para ello permitió que dos o tres naturales varones, «pero nunca una mujer», llevaran un cajoncito con la imagen del san Agustín hasta el puerto de Acapulco y 20 leguas al contorno. En la licencia el prelado aclaró que: «para dicho puerto se entiende yendo una recta y pasando por los pueblos del obispado de Puebla». Razón por la cual rogaba a

20 Por ejemplo en Sacatepec había más de 220 personas. 
los ministros de aquella jurisdicción eclesiástica no impedir el paso. De hecho el arzobispo reconoció la «suma pobreza 'de las iglesias y capillas de la parte Sur del arzobispado' por lo que prohibió no recolectar 'mas limosnas para el Santuario de San Miguel del Milagro en Puebla' para que éstas se dedicaran al aderezamiento de sus propios templos $\gg^{21}$.

En algunos casos, Aguiar y Seijas, no dio licencia de limosnas pero sí autorización para reconstruir o restablecer nuevas jurisdicciones parroquiales, de esta manera autorizó al Pueblo de Papula (sujeto a Tepecuacuilco) a reconstruir y reedificar su iglesia que se había arruinado a consecuencia de que habían despoblado el pueblo «desde las congregaciones». El arzobispo dio licencia y decretó además que todos los fieles de ese poblado pudieran en dicho lugar ser bautizados y enterrados en virtud de que la cabecera estaba a seis leguas de distancia. Y es que redefinir jurisdicciones eclesiásticas aseguraba la mejor administración de los sacramentos a los fieles, esto último que era parte esencial y medular de la reforma tridentina. El arzobispo, además, no solo redefinió jurisdicciones ${ }^{22}$, sino además, en orden a configurar en los fieles los postulados tridentinos promovió durante la visita devociones, supervisó y dio constituciones a las numerosas cofradías, participó durante la visita en diversos actos devocionales y sancionó prácticas heterodoxas.

En el primer caso por ejemplo, otorgó licencia a los esclavos del ingenio de Santiago Tenespongo para pedir limosna para el culto de la imagen de su devoción: Nuestra Señora de la Soledad. En el segundo caso el prelado revisó y supervisó los libros, cuentas, y constituciones o formuló nuevos reglamentos para las 35 cofradías que visitó, de la cuales 13 eran de naturales (una de ellas de naturales e indios caciques ubicada en Cuernavaca), dos de mulatos, tres de españoles y una de morenos, la de nuestra señora de la Soledad, también con sede en Cuernavaca. La mayoría de las cofradías eran marianas, al menos veinte de ellas, cinco estaban dedicadas a santos, cuatro al santísimo sacramento, tres a las ánimas del purgatorio y tres a la doctrina cristiana, como se ve en el cuadro 2 .

21 Otra licencia para construir la iglesia la da a los naturales de san Francisco Texalpa. Les otorga un año para perfeccionar y acabar las iglesias y sacristía. Al pueblo de San María (doctrina de Cuernavaca) le otorga licencia de limosna por un año para culto y ornato de su iglesia

22 Además del ejemplo anterior redefine jurisdicciones en Oapan y en un Trapiche, el de Culiscaguacan. Autoriza que este último sea administrado por Cacaltenango de Taxco. 
Cuadro 2. Cofradías supervisadas por el arzobispo en su visita al Sur²3

\begin{tabular}{|c|c|c|c|}
\hline Cofradía & Calidad & Parroquia & Auto \\
\hline $\begin{array}{l}\text { Doctrina Cristiana y } \\
\text { Santo Entierro }\end{array}$ & $\begin{array}{l}\text { Indios } \\
\text { cantores }\end{array}$ & $\begin{array}{l}\text { San Agustín de las } \\
\text { Cuevas }\end{array}$ & $\begin{array}{l}\text { lleven cuentas bien, no gasten } \\
\text { en toros, danzas, chocolates }\end{array}$ \\
\hline $\begin{array}{l}\text { hermandad del } \\
\text { Santísimo Sacramento }\end{array}$ & & Xochitepec & \\
\hline Santísimo Sacramento & Naturales & $\begin{array}{l}\text { San Lucas de } \\
\text { Masaltepec }\end{array}$ & \\
\hline $\begin{array}{l}\text { Nuestra Señora de la } \\
\text { Natividad }\end{array}$ & Naturales & Amasetepec & $\begin{array}{l}\text { no gastos en chocolates, } \\
\text { comidas, bebidas, toros, } \\
\text { colaciones }\end{array}$ \\
\hline $\begin{array}{l}\text { Nuestra Señora de la } \\
\text { Asunción }\end{array}$ & Naturales & Amasetepec & $\begin{array}{l}\text { no gastos en chocolates, } \\
\text { comidas, bebidas, toros, } \\
\text { colaciones }\end{array}$ \\
\hline $\begin{array}{l}\text { Cofradía de la } \\
\text { Concepción de } \\
\text { naturales }\end{array}$ & Naturales & Atenango del río & $\begin{array}{l}\text { no gastos en chocolates, } \\
\text { comidas, bebidas, toros, } \\
\text { colaciones }\end{array}$ \\
\hline $\begin{array}{l}\text { Cofradía preciosa } \\
\text { Sangre de cristo y } \\
\text { ánimas del purgatorio } \\
\text { del Chilpancingo }\end{array}$ & & Zupango del Río & $\begin{array}{l}\text { lleven bien cuentas, no gastos } \\
\text { en danzas, colaciones, juegos, } \\
\text { toros }\end{array}$ \\
\hline Cofradía de Asunción & Naturales & Zupango del Río & $\begin{array}{l}\text { lleven bien cuentas, no gastos } \\
\text { en danzas, colaciones, juegos, } \\
\text { toros }\end{array}$ \\
\hline $\begin{array}{l}\text { Cofradía de la } \\
\text { Natividad }\end{array}$ & Naturales & Zupango del Río & les da constituciones, no gastos \\
\hline San Nicolás Tolentino & Mulatos & Zumpango del Río & $\begin{array}{l}\text { les da constituciones y que sea } \\
\text { de todas las calidades }\end{array}$ \\
\hline $\begin{array}{l}\text { Cofradía de la } \\
\text { natividad de la Virgen }\end{array}$ & Naturales & Zumpango del Río & $\begin{array}{l}\text { les da constituciones, cuide de } \\
\text { gastos }\end{array}$ \\
\hline $\begin{array}{l}\text { Nuestra Señora de la } \\
\text { Asunción }\end{array}$ & Naturales & $\begin{array}{l}\text { Santa María } \\
\text { Concepción } \\
\text { Tepecuauilco }\end{array}$ & \\
\hline $\begin{array}{l}\text { Nuestra Señora de la } \\
\text { Concepción }\end{array}$ & & $\begin{array}{l}\text { Santa María } \\
\text { Concepción } \\
\text { Tepecuauilco }\end{array}$ & contaba con cabezas de ganado \\
\hline
\end{tabular}

23 El notario en algunas ocasiones no asentó la calidad de las personas que conformaban la cofradía, es decir, si era de naturales, de negros o mixta. 


\begin{tabular}{|c|c|c|c|}
\hline Cofradía & Calidad & Parroquia & Auto \\
\hline $\begin{array}{l}\text { Nuestra Señora de la } \\
\text { Natividad }\end{array}$ & Naturales & $\begin{array}{l}\text { Pueblo de } \\
\text { Guiseltepec. beneficio } \\
\text { de Tlacotepec }\end{array}$ & \\
\hline San Nicolás Tolentino & $\begin{array}{l}\text { mulatos de la } \\
\text { ranchería de } \\
\text { Izquierda }\end{array}$ & $\begin{array}{l}\text { Iglesia de } \\
\text { Chilpancingo }\end{array}$ & se les da constituciones \\
\hline $\begin{array}{l}\text { Cofradía de la } \\
\text { concepción del Pueblo } \\
\text { de Tuxpa }\end{array}$ & & Tuxpa & \\
\hline $\begin{array}{l}\text { Nuestra Señora de a } \\
\text { Concepción }\end{array}$ & Naturales & Cocula & $\begin{array}{l}\text { Piden constituciones porque se } \\
\text { quemaron las suya, tiene } 106 \\
\text { cabezas de ganado }\end{array}$ \\
\hline $\begin{array}{l}\text { Nuestra Señora de la } \\
\text { Asunción }\end{array}$ & & $\begin{array}{l}\text { San Francisco de } \\
\text { Iguala }\end{array}$ & \\
\hline $\begin{array}{l}\text { Cofradía de Nuestra } \\
\text { Señora }\end{array}$ & & $\begin{array}{l}\text { San Francsico de } \\
\text { Iguala }\end{array}$ & \\
\hline Cofradía del Rosario & Naturales & $\begin{array}{l}\text { San Domingo } \\
\text { Tlalquitenango }\end{array}$ & no hagan gastos superfluos \\
\hline $\begin{array}{l}\text { Hermandad del } \\
\text { Gloriosos San Nicolás } \\
\text { Tolentino }\end{array}$ & $\begin{array}{l}\text { mulatos y } \\
\text { mestizos }\end{array}$ & $\begin{array}{l}\text { San Miguel } \\
\text { Tlaltizapan }\end{array}$ & \\
\hline Cofradía del Rosario & & $\begin{array}{l}\text { San Miguel } \\
\text { Tlaltizapan }\end{array}$ & \\
\hline $\begin{array}{l}\text { Cofradía de San } \\
\text { Miguel Arcángel y } \\
\text { animas del Pulgatorio }\end{array}$ & & $\begin{array}{l}\text { San Miguel } \\
\text { Tlaltizapan }\end{array}$ & $\begin{array}{l}\text { constituciones, cuenta con } 300 \\
\text { ovejas }\end{array}$ \\
\hline $\begin{array}{l}\text { Cofradía de San } \\
\text { Francisco }\end{array}$ & & Santiago Xiutepec & \\
\hline $\begin{array}{l}\text { Cofradía de Nuestra } \\
\text { Señora de la Limpia } \\
\text { Concepción }\end{array}$ & & Santiago Xiutepec & erigió como cofradía \\
\hline $\begin{array}{l}\text { Cofradía de Ánimas } \\
\text { del purgatorio y San } \\
\text { Antonio de Padua, } \\
\text { agregada a la doctrina } \\
\text { Cristiana }\end{array}$ & & Santiago Xiutepec & \\
\hline
\end{tabular}




\begin{tabular}{lll}
\multicolumn{1}{c}{ Cofradía } & \multicolumn{1}{c}{ Calidad } & \multicolumn{1}{c}{ Parroquia } \\
Cofradía del Santísimo \\
$\begin{array}{l}\text { Sacramento y nuestra } \\
\text { Señora de la Asunción } \\
\text { y su glorioso transito }\end{array}$ & & Santiago Xiutepec \\
\hline $\begin{array}{l}\text { Cofradía de las } \\
\text { benditas animas del } \\
\text { purgatorios }\end{array}$ & Españoles & Cuernavaca \\
\hline $\begin{array}{l}\text { Cofradía del Santísimo } \\
\text { Sacramento }\end{array}$ & Españoles & Cuernavaca \\
\hline $\begin{array}{l}\text { Nuestra Señora de la } \\
\text { Soledad }\end{array}$ & Morenos & Cuernavaca \\
\hline $\begin{array}{l}\text { Cofradía del Santísimo } \\
\text { Sacramento }\end{array}$ & Naturales & Cuernavaca \\
\hline $\begin{array}{l}\text { Cofradía del Glorioso } \\
\text { San Diego }\end{array}$ & Naturales & Cuernavaca \\
\hline $\begin{array}{l}\text { Cofradía de Nuestra } \\
\text { Señora de la } \\
\text { Concepción }\end{array}$ & $\begin{array}{l}\text { Naturales } \\
\text { principales } \\
\text { caciques }\end{array}$ & Cuernavaca \\
\hline $\begin{array}{l}\text { Cofradía de nuestra } \\
\text { Señora de la limpia } \\
\text { y pura Concepción, } \\
\text { agregada a la doctrina } \\
\text { cristiana de San Felipe }\end{array}$ & Españoles & Cuernavaca \\
\hline
\end{tabular}

De las 35 cofradías que supervisó al menos nueve, como se puede apreciar en el cuadro, fueron reconvenidas y advertidas de que no se reconocerían aquellos gastos que presentaran por bailes, comidas, chocolates, toritos o colaciones.

En orden a configurar los preceptos de Trento, Aguiar y Seijas, también celebró y concelebró varias misas, presidió el rezo de más de 40 rosarios, bendijo, con el respectivo rito, 101 campanas y realizó diversas ceremonias para confirmar a más de 13.126 fieles $^{24}$. Además, participó en distintas procesiones: en Tepecuacuilco, presidió la procesión de la virgen y en Cuernavaca asistió a las procesiones «de la misión, a las de sangre y a la de penitencia». En la procesión de la misión anduvo por las calles de aquella villa donde se pronunciaron saetas espirituales y

24 En su visita a Chalco / Xochimilco celebrada en 1686 y 1687 confirmó a 34968 fieles. El dato anterior es para ilustrar la diferencia en la densidad de población de una y otra zona 
platicas en castellano y mexicano hasta las nueve de la noche. En suma, el arzobispo hizo de esta visita un espacio y un tiempo de sacralidad con el fin de regular y configurar los postulados de Trento entre los fieles.

Ahora bien, Como hemos dicho, el cuidado de la ortodoxia era parte esencial de la visita. De hecho y por lo tanto, acompañado de la carta derrotero en la que se indicaba las parroquias sujetas a visita, sabemos que se expedía también un edicto de pecados públicos. En él se indicaba que el objetivo principal de la visita era «ver y reconocer» cómo era la administración de los sacramentos, de qué manera se impartía la doctrina a los fieles y cómo era la conducta de éstos y de los eclesiásticos para que las corrigiera, castigara o remediara sí en «algunas cosas se falta». Por esta razón a través del edicto se conminaba a todos los ministros y feligreses a presentarse durante la visita a «decir, declarar, revelar o manifestarse» en contra de aquellos eclesiásticos que no cumplieran con las obligaciones precisas de su ministerio o aquellos fieles que hubieren cometido pecados públicos como decir blasfemias, cometer apostasía, ser hechiceros, brujos o supersticiosos, estar casados dos veces o en grado prohibido, estar casado sin amonestaciones o denunciar a quienes hacían vida madirable sin tener el sacramento del matrimonio, poseyeran oratorios sin licencia o comieran carne en Vigilia o Cuaresma sin que para ello tuvieran licencia médica o espiritual ${ }^{25}$.

Aguiar y Seijas en cumplimiento de este edicto y para erradicar las «malas costumbres» pidió durante la visita, por ejemplo, un informe pormenorizado a los dueños de haciendas, trapiches y obrajes de aquellos negros esclavos que estuvieran en «mal estado» y que por falta de dinero no hubiesen celebrado el sacramento del matrimonio. Sobre este sacramento es de hacer notar las numerosas dispensas de banas, es decir de la dispensa de la lectura de amonestaciones públicas, que otorgó para que determinados fieles pudiesen celebrarlo y la forma en que aprobó y ratificó el matrimonio de ocho indios bozales en la capilla del ingenio de Miacatlan que se ubicaba en la parroquia de San Lucas Masaltepec. Asimismo, procuró que «los últimos sacramentos», es decir la extremaunción y entierro. Se cumplieran como lo disponía el ritual tidentino, de allí que prohibiera

25 En suma, mientras en la carta cordillera se indicaba la forma, las circunstancias, los medios para realizar la visita, así como los espacios, corporaciones, y manuscritos que serían revisados, en el edicto de pecados se exponía qué conductas y prácticas, de fieles y eclesiásticos, debían ser denunciadas por no cumplir los postulados tridentinos. En ambos documentos es claro notar que el objeto principal de la visita era hacer cumplir lo dispuesto por Trento. Berenise BRAVO RUBIO y Marco Antonio PÉREZ ITURBE, Una práctica un manuscrito. Los libros de visitas pastorales de fosé Lanciego y Eguilaz al arzobispado de México (1715-1720), en Rodolfo AGUIRRE (coord.), Visitas pastorales del arzobispado de México, 1715-1722, México, 2016, 40-53. 
severamente que solo los cantores enterraran a un fiel difunto sin la participación de los curas ministros. También prohibió que los cantores fueran usados como «correos»y que las mujeres entraran a la iglesia y el cementerio con capotillos encarnados, sombreros o mantelillos. El arzobispo además alentó en todas las parroquias a los curas y doctrineros a enseñar adecuadamente la doctrina cristiana para evitar errores.

Pero además de atender asuntos de gobierno propios de las parroquias sujetas a la visita, el arzobispo, con ayuda de sus notarios y eclesiásticos, atendió otros de otras parroquias. Es decir, en una especie de curia itinerante, solucionó diversos asuntos que no competían a ninguno de los curatos sujetos a visita como veremos a continuación

\section{UNA CURIA ITINERANTE}

Algunas veces el cuidado de la ortodoxia no tenía que ver con parroquias que visitaba sino con informes que le llegaban de otros curatos. Así que durante la visita el arzobispo despachaba asuntos de gobierno de todo su arzobispado, es decir se convertía él y su sequito en una mitra itinerante, de tal forma que por ejemplo, desde la parroquia de Tepecuacuilco expidió un edicto prohibiendo que en Toluca se celebraran «cañas, escaramuzas, toros, se vistieran como moros y cristianos o pusieran enramadas en el campo santo» y solicitó que solo se llevaran a cabo procesiones con decencia y danzas serias como lo tecotines y que las misas se celebraran solamente en las iglesias o capillas autorizadas. Asimismo el arzobispo despachó «comisión y facultad» a los ministros de doctrina o en su caso al coadjutor guardián o ayudante para que levantaran las informaciones matrimoniales de españoles, negros mulatos y vecinos de la doctrina de Huichapan, Coyoacan, Toluca, Metepec, Calimaya y Sinacantepec. Con ello pretendía que todos los fieles cumplieran con los requisititos para celebrar adecuadamente el sacramento del matrimonio. Este punto, el del sacramento del matrimonio, parecía preocuparle enormemente al prelado ya que en todas las visitas que realizó buscó poner en «orden» las relaciones en las que no mediaba el sacramento y extendió las licencias a los frailes o las delegó a los jueces eclesiásticos para que pudieran coadyuvar a ello levantando unos y otros las informaciones matrimoniales. En el primer caso, por ejemplo, dio y autorizó, a Bernabé Godinez y Antonia Espinoza, feligreses de la parroquia de Huichapan, las dispensas de amonestaciones con el fin de que pudieran casarse a la brevedad posible en virtud de que él, español natural de Puebla, «debajo de palabra de casamiento hizo su 
honor Antonia», y la «sacó de su casa». En el segundo caso, decretó durante la visita varios edictos como aquel en el que ordenó que el Juez eclesiástico de la parroquia de Churubusco que llevara a cabo las informaciones matrimoniales de los feligreses vagos, es decir, de los fieles no residentes en aquella parroquia. Para hacer cumplir adecuadamente los sacramentos también expidió un edicto en San Agustín de las Cuevas prohibiendo que en Xochimilco durante los entierros no sólo estuvieran los cantores sino invariablemente los curas párrocos. $\mathrm{El}$ arzobispo mandó que este edicto en particular fuera dado «a entender» en el propio idioma de los naturales

\section{CONCLUSIÓN}

El arzobispo regresó a la ciudad de México, después de dos meses, sin lograr tocar el puerto de los reyes Acapulco. La visita le permitió tener una relación puntual sobre el estado de la iglesia, es decir, de su ministros, fieles, espacios de culto y prácticas religiosas a finales del siglo XVII, del avance y esfuerzo por establecer la iglesia diocesana en virtud de que reconoció el trabajo de los cinco eclesiásticos seculares y otorgó el nombramiento a siete como jueces eclesiásticos, es decir, como jueces delegados de la autoridad ordinaria o episcopal ${ }^{26}$; Asimismo reconoció el papel de los religiosos como curas de almas no sin antes pedirles encarecidamente que predicaran adecuadamente la doctrina. También durante la visita redefinió espacios eclesiásticos como una estrategia para configurar las directrices de Trento a través de la diligente administración de los sacramentos y puntualmente constató que la denominada zona del Sur era completamente desigual y contrastante entre los fértiles valles de Cuernavaca, en donde abundaban los trapiches, los ingenios y las hacienda, con respecto a las pobre zonas de la jurisdicción de Iguala o Tixtla donde con sorpresa descubrió, por ejemplo, que carecían de pila bautismal y que usaban en lugar de ella un vasija maltrecha de barro. Una no grata sorpresa para un prelado configurado por el concilio de Trento, concilio que estableció que la decencia, el ornato eran «señales visibles» que indicaban al fiel que recibía una gracia sensible.

26 Los jueces nombrados fueron: Bernardo de Periglosa para San Agustín de las Cuevas, Alonso de Alanis para Tasmalac, Juan Sánchez Almazan para Atenango de Río, Francisco Herrera para Oapan, Manuel Tellez Xirón para Zupango del Río, Juan Rivera para Tepecoacuilco, Alonso Álferez en Cuernavaca. 
Si bien es cierto que el arzobispo, a propósito de configurar los postulados tridentinos entre los fieles, participó durante toda la visita en innumerable misas, ceremonias y ritos y con ello abrió un tiempo y un espacio sacralizado, también lo es el que nunca dejó, durante el transcurso de ella, de decidir y resolver asuntos del gobierno local o de otras parroquias de su jurisdicción es decir, de funcionar como mitra itinerante. En suma, sacralidad y gobierno son las palabras que definen la visita de Aguiar y Seijas al agreste y desolado Sur del Arzobispado de México.

\section{REFERENCIAS BIBLIOGRÁFICAS}

\section{Bibliografía}

Bravo Rubio, Berenise y PÉReZ ItUrbe, Marco Antonio, Tiempos y Espacios religiosos novobispano. La visita pastoral de Francisco Aguiar y Seijas 1683-1684, en Alicia MAYER y Ernesto DE La TORRe Del Villar (coords.), Religión, poder y sociedad en la Nueva España, México, 2004, pp. 67-83.

- Una práctica un manuscrito. Los libros de visitas pastorales de fosé Lanciego y Eguilaz al arzobispado de México (1715-1720), en Rodolfo AGUIRRE (coord.), Visitas pastorales del arzobispado de México, 1715-1722, México, 2016, pp. 40-53.

CARILlo CaZARES, Alberto, El obispo Aguiar y Seijas: su perfil pastoral en Michoacán (16781682), en Josefina MURIEL, el arzobispo Francisco Aguiar y Seijas, México, 2000, pp. 27 a 46.

— Michoacán en el otoño del siglo XVII, Morelia Michoacán, 1993.

DE La FloR, Fernando Barroco. Representación e ideología en el mundo hispano (1580-1680), España, 2002, p. 163

GERHARD, Peter, Geografía Histórica de la Nueva España 1519-1821, México, 1986, p 151

RUBIAL GARCía, Antonio, Las monjas se inconforman: los bienes de Sor Fuana en el espolio del arzobispo Francisco Aguiar y Seijas, en Biblioteca Virtual Universal (2005).

Silva Herrera, Rocío, Francisco Aguiar y Seijas, pastor del rebaño, en Cuadernos de estudios Gallegos, LXI, no. 127 (enero-diciembre de 2014), pp. 117-142

\section{Archivos}

Archivo General de la Nación, México. Ramo Bienes Nacionales Archivo Histórico del Arzobispado de México. Fondo episcopal Biblioteca Nacional. Fondo Reservado La Fragua de la. 